\title{
Impaired Mucosal Integrity in Proximal Esophagus Is Involved in Development of Proton Pump Inhibitor-Refractory Nonerosive Reflux Disease
}

\author{
Kazuaki Norita ${ }^{a}$ Kiyotaka Asanuma ${ }^{a}$ Tomoyuki Koike ${ }^{a}$ Tomoki Okata $^{a}$ \\ Taku Fujiya $^{a}$ Yasuaki Abe ${ }^{a}$ Kenichiro Nakagawa ${ }^{a}$ Waku Hatta ${ }^{a}$ \\ Kaname Uno ${ }^{a}$ Tomohiro Nakamura ${ }^{b}$ Naoki Nakayab Naoki Asano ${ }^{a}$ \\ Akira Imatani $^{a}$ Tooru Shimosegawa ${ }^{a}$ Atsushi Masamune ${ }^{a}$ \\ aDivision of Gastroenterology, Tohoku University Graduate School of Medicine, Sendai, Japan; ${ }^{b}$ Division of \\ Personalized Prevention and Epidemiology, Department of Preventive Medicine and Epidemiology, Tohoku Medical \\ Megabank Organization, Tohoku University, Sendai, Japan
}

\section{Keywords}

Acid hypersensitivity · Nonerosive reflux disease .

Proton pump inhibitor refractory · Proximal esophagus .

Transepithelial electrical resistance

\begin{abstract}
Background and Objective: Weakly acidic reflux reaching to the proximal esophagus is closely related to the perception of gastroesophageal reflux in patients with nonerosive reflux disease despite treatment with a proton pump inhibitor (PPI). However, little is known about the involvement of the patients' mucosal integrity of the proximal esophagus. Methods: We recruited 15 symptomatic nonerosive gastroesophageal reflux disease (GERD) patients with a positive symptom index despite PPI treatment and 11 healthy asymptomatic volunteers as controls. The biopsy specimens obtained from the proximal and distal esophagus were applied to a mini-Ussing chamber system to measure transepithelial electrical resistance (TEER) against a pH 4 weak acid.
\end{abstract}

karger@karger.com www.karger.com/dig

Karger $\frac{1}{\%}$

BOPEN ACCESS
(C) 2020 The Author(s)

Published by S. Karger AG, Basel

This article is licensed under the Creative Commons AttributionNonCommercial-NoDerivatives 4.0 International License (CC BYNC-ND) (http://www.karger.com/Services/OpenAccessLicense) Usage and distribution for commercial purposes as well as any distribution of modified material requires written permission.
The esophageal biopsy samples were subjected to quantitative real-time PCR and immunohistochemical analysis. $\boldsymbol{R e}$ sults: In the proximal esophagus, the weak acid exposure reduced the TEER in the PPI-refractory patients compared to that in the controls. The frequency of the reflux extending to the proximal esophagus had a significant correlation with the reduction in the proximal esophageal TEER in the patients. The reduced TEER in the proximal esophagus was accompanied by an increase in $I L-8$ and $I L-1 \beta$ mRNA and a decrease in occludin mRNA levels. The proximal esophageal mucosa in the patients presented infiltration of CD3-positive lymphocytes and an increased expression of solute carrier organic anion transporter family member $2 \mathrm{~A} 1$ (SLCO2A1), a passage gate of reflux symptom-evoking molecules. Conclusions: The reflux perception is related to an impairment of the proximal esophageal mucosal integrity in patients with nonerosive reflux disease despite PPI.

(C) 2020 The Author(s)

Published by S. Karger AG, Basel 


\section{Introduction}

Gastroesophageal reflux disease (GERD) has become more common, and the prevalence now reaches to $20 \%$ of the Japanese population. One of the accountable reasons is that the prevalence of Helicobacter pylori infection is decreasing, which increases gastric acid secretion in the Japanese $[1,2]$. The diagnosis of GERD depends on diverse techniques, and esophagogastroduodenoscopy (EGD) is frequently used in Japan. An epidemiologic study using EGD in Japan revealed that the distal esophagus in almost one-half of patients with gastroesophageal reflux symptoms manifests mucosal injury, categorized as erosive esophagitis (ERD) [3]. The treatment response to antacid therapy such as proton pump inhibitor (PPI) reaches as high as $80 \%$ in ERD patients $[4,5]$. However, the treatment response for the rest of them is controversial. A noteworthy clinical feature is that $<70 \%$ is the reported response rate in nonerosive GERD patients including those with reflux hypersensitivity $[6,7]$. In the clinical setting, this PPI failure in such patients is urgent to be solved since many of them diminish the quality of life [8].

Using animal models simulating GERD, we demonstrated that noxious substances, including acid in the esophageal lumen, injured the epithelial microstructure and reduced transepithelial electrical resistance (TEER), a reliable indicator of mucosal integrity $[9,10]$. Moreover, measurement of the TEER in human esophageal biopsies allows us to evaluate mucosal integrity in both basal conditions and continuous response to reagents such as acid stimulus. A recent study using human biopsy specimens demonstrated that reduced TEER of the distal esophagus in PPI-refractory heartburn patients without ERD contributes to the acid perception [11]. Esophageal mucosal integrity is an important barrier function against gastroesophageal reflux, and attenuation of this function could facilitate the permeation of noxious substances of the refluxate into the deeper epithelium, leading to the activation of nociceptors despite the lack of apparent visible mucosal damage [12]. This persuasive explanation, however, remains controversial for fully elucidating the mechanism of heartburn symptoms in GERD. Although severe noxious or strong acid refluxate apparently decreased esophageal TEER and aggravated mucosal damage compared to weakly acidic stimulants [13], the severity of esophageal mucosal damage was not often in parallel with the degree of heartburn symptoms in patients with ERD [14]. These findings suggest that distinct or additional underlying mechanisms are responsible for reflux-related symptoms in nonerosive GERD patients.

Damaged Mucosal Barrier Function

Results in Hypersensitivity to Weak Acid
The development of reflux symptoms despite the absence of macroscopical mucosal damages in the esophagus was associated with altered gene expression of proinflammatory cytokines and tight junctional molecules such as IL-1 $\beta$, IL-8, and occludin (OCLN) $[15,16]$. Moreover, transient receptor potential cation channel subfamily $\mathrm{V}$ member 1 (TRPV1), an acid-sensing nociceptor, was increased in GERD patients [17]. Additionally, we evaluated the esophageal tissue expression of solute carrier organic anion transporter family member $2 \mathrm{~A} 1$ (SLCO2A1), a core component of the channel for releasing pain-inducing molecules such as adenosine $5^{\prime}$-triphosphate (ATP) and prostaglandin E2 (PGE2), which are involved in the GERD pathogenesis as well as reflux symptoms [18-20]. However, whether these genes are involved in the esophageal reflux perception despite PPI medication in patients with nonerosive reflux disease remains elusive.

A previous study demonstrated that proximal spread of weakly acid reflux determines the perception of reflux in GERD patients without apparent esophageal injury on PPI therapy $[21,22]$. Then, we recently revealed that the proximal extent of weakly acidic reflux is critical to the perception of reflux in patients with nonerosive reflux disease despite the use of PPIs [23]. Thus, we hypothesized that an alternation in esophageal mucosal integrity by location could be associated with acid hypersensitivity, which causes reflux perception in the patients. Using a mini-Ussing chamber system, the current study aimed to clarify how mucosal integrity in the proximal esophagus contributes to the induction of reflux symptoms in PPIrefractory nonerosive reflux disease.

\section{Materials and Methods}

\section{Subjects}

We enrolled subjects from among 29 PPI-refractory patients with nonerosive reflux disease who were identified as having a positive symptom index (SI) for liquid reflux episodes during PPI treatment by 24 -h multichannel intraluminal impedance combined $\mathrm{pH}$ monitoring (24-h MII-pH monitoring), which was performed in 62 patients with PPI-refractory reflux symptoms without erosive esophagitis, in Tohoku University Hospital from August 2017 to August 2018. All the patients did not have any esophageal erosion at EGD without PPI use before the entry. PPIrefractoriness was defined as having symptoms suggestive of gastroesophageal reflux that persisted despite taking $10 \mathrm{mg}$ of rabeprazole twice daily for at least 8 weeks and a score on the FSSG (frequency scale for symptoms of gastroesophageal reflux disease) higher than 8 [24]. All studies were conducted without discontinuing their PPI treatment. Of the 62 patients, 5 were excluded since no reflux symptoms were observed in the 24-h MII-pH monitor- 
ing. Written informed consent was obtained from all subjects prior to study entry. Ultimately, 15 consecutive PPI-refractory patients with nonerosive reflux disease participated in the current study. As controls, we recruited 11 nonsymptomatic healthy volunteers without any medication or endoscopic manifestations in the upper gastrointestinal tract including esophagus. Subjects with peptic ulcer disease, malignant disease, or a history of previous esophagogastric surgery prior to the endoscopic examination were excluded from the current study.

\section{Impedance-pH Equipment}

To assess gastroesophageal reflux in the patients with PPI-refractory reflux perception, 24-h MII-pH monitoring was performed as previously reported $[22,23]$. The data obtained from the patients using ConforTec MII/pH (Sandhill Scientific, Highland Ranch, CO, USA) were analyzed independently by 2 authors (Y.A. and K.T.) with Bioview Analysis version 5.4.3 (Sandhill Scientific). Reflux events were divided into 3 subcategories based on the esophageal luminal $\mathrm{pH}$ level at the point of reflux: acid reflux $(\mathrm{pH}$ $\leq 4)$, weakly acidic reflux $(4<\mathrm{pH}<7)$, and weakly alkaline reflux $(7 \leq \mathrm{pH})$. Nonerosive reflux disease were defined as SI positive if there was a positive correlation between reflux (acid or weakly acidic reflux) and episodes of typical GERD symptoms (both SI $>50 \%$ ) according to a previous study [25]. In the present study, we defined heartburn and/or regurgitation as typical GERD symptoms and used them for the evaluation of SI. Proximal reflux was defined if the impedance indicated liquid reflux at $17 \mathrm{~cm}$ above the LES.

\section{Endoscopic Examination}

On the day of upper gastrointestinal endoscopic examination, the symptoms of the PPI-refractory patients were assessed by the FSSG, a questionnaire for the diagnosis of reflux disease. After obtaining clinical information such as gender, age, and BMI, all subjects underwent endoscopic examination without stopping PPI use. The degree of gastric mucosal atrophy was evaluated using the classification of Kimura and Takemoto and categorized into 3 groups: none-mild (none, $\mathrm{C}-1$, and C-2), moderate (C-3, O-1), or severe (O-2, O-3) [26]. Then, 2 esophageal mucosal biopsies per patient, $3-4 \mathrm{~mm}$ in size, were obtained using a biopsy forceps which has 6.7-mm-opening jaw size (No.10 Gaoke Third Road, Micro-Teck, Jiansu, China), one from the distal esophagus ( $3 \mathrm{~cm}$ above the squamocolumnar junction) and the other from the proximal esophagus $(17 \mathrm{~cm}$ above the squamocolumnar junction). The biopsy specimens were immediately washed in ice-cold oxygenated modified Krebs buffer [27] and then applied to the mini-Ussing chamber system within $5 \mathrm{~min}$. After the Ussing chamber analysis, the samples were used for quantitative real-time polymerase chain reaction (qRTPCR) experiments. Additionally, proximal esophageal tissue samples were obtained from each group of 5 people for histological examination. These samples were fixed in formalin and embedded in paraffin for hematoxylin-eosin and immunohistochemical staining.

\section{Electrophysiological Measurement of TEER}

The ex vivo mucosal integrity was measured using a miniUssing chamber system (EM-CYSY-2 Ussing Chamber Systems, Physiologic Instruments, San Diego, CA, USA) and 2-channel voltage clamp with a preamplifier system (EVC4000-2, Physiolog- ic Instruments) as previously reported [27]. Esophageal biopsy samples were first orientated by using a magnifying loupe to determine the luminal side from the serosal side and then set on a tissue mounting slide (Ussing Slider P2308, Physiologic Instruments) which has a 1 -mm-diameter circular aperture (area $\left.=0.0079 \mathrm{~cm}^{2}\right)$. In our preliminary study, the orientation was confirmed microscopically in formalin-fixed tissues with red marking dye (data not shown). The TEER was determined using Ohm's law by passing a $10-\mu \mathrm{A}$ current through the membrane and measuring the change in the transepithelial electrical potential difference. After samples were acclimatized with pH7.4 oxygenated Krebs buffer at $37^{\circ} \mathrm{C}$ for $30 \mathrm{~min}$, the compartment on the mucosal side was perfused with normal saline, the $\mathrm{pH}$ of which was adjusted to 4.0 with hydrochloric acid, and the compartment on the serosal side was perfused with the Krebs buffer. The TEER using 2 biopsy samples obtained from the proximal and distal esophagus was measured simultaneously every $15 \mathrm{~min}$ over a period of $180 \mathrm{~min}$. Values are expressed as percentages of change in resistance from baseline (time $=0)$. For the subsequent experiment to investigate mRNA expression levels, mounted specimens were immersed in liquid nitrogen and stored at $-80^{\circ} \mathrm{C}$ until RNA extraction.

\section{Quantitative Real-Time Polymerase Chain Reaction}

Total RNA was isolated from the esophageal biopsy specimens using TRIzol Reagent (Thermo Fisher Scientific, Waltham, MA, USA) following the manufacturer's instructions, and first-strand cDNA was synthesized using a SuperScript ${ }^{\circledR}$ VILO $^{\mathrm{TM}}$ cDNA Synthesis kit (Thermo Fisher Scientific). qRT-PCR was performed using a StepOnePlus Real-Time PCR system (Applied Biosystems, Carlsbad, CA, USA) with SYBR green I (PowerSYBR Green PCR Master Mix; Applied Biosystems). The sequences of the oligonucleotide primers (forward and reverse, respectively) are as follows: IL-8 (5' ${ }^{\prime}$-CTTGGCAGCCTTCCTGATTT- ${ }^{\prime}$ and $5^{\prime}$-TTCTTTAGCACTCCTTGGCAAAA- $\left.3^{\prime}\right), I L-1 \beta$ ( $5^{\prime}$-TCGCCAGTGAAAGAT GGCT- $3^{\prime}$ and $5^{\prime}$-GGTCGGAGATTCGTAGCTGG-3'), OCLN (5'-AACTCGAAG AAAGATGGACAGGT- $3^{\prime}$ and $5^{\prime}$-CCACA TAGTCAGATGGGGGTG- $\left.3^{\prime}\right)$, TRPV-1 (5'-GAGAGACCTGTGCCGTTTCA- $3^{\prime}$ and $5^{\prime}$-TCCCGTCTTCAATCAGCGTC- $3^{\prime}$ ), SLCO $2 A 1$ ( $5^{\prime}$-CCTTCGTGTCCCTGATAGCC- $3^{\prime}$ and $5^{\prime}$-ACCCC GATGGCAAATGA CTT-3'), and glyceraldehyde-3-phosphate dehydrogenase (GAPDH) (5'-TCGACAGTC AGCCGCATCT-3' and $5^{\prime}$-AGTTAAAAGCAGCCCTGGTGA-3'). mRNA expression levels were normalized to those in GAPDH. Fold changes in patients relative to controls were calculated based on the delta-delta CT method.

\section{Immunohistochemistry}

Paraffin-embedded sections of $4 \mu \mathrm{m}$ were deparaffinized and rehydrated with xylene and a graded alcohol series. The sections were immersed in 3\% hydrogen peroxide in methanol for $10 \mathrm{~min}$ to block endogenous peroxidase activity, followed by antigen retrieval with a target retrieval solution (Dako, Glostrup, Denmark) done by pressure cooking at $125^{\circ} \mathrm{C}$ for $5 \mathrm{~min}$. The primary antibodies and their dilutions used for $4^{\circ} \mathrm{C}$ overnight incubation are as follows: CD3 (rabbit, ready-to-use, DAKO), CD34 (mouse, 1:100, Nichirei Bioscience, Tokyo, Japan), and SLCO2A1 (rabbit, 1:200, ATLAS ANTIBODIES, Bromma, Sweden). Color development was performed using EnVision ${ }^{\mathrm{TM}}$ FLEX (DAKO) for CD3 and simple stain MAX-PO (Nichirei Bioscience) for CD34 and SLCO2A1, followed by counterstaining with hematoxylin. 
Table 1. Clinical features of the enrolled subjects

\begin{tabular}{llcc}
\hline & Control & Patient & $p$ value \\
\hline Subjects, $n$ & 11 & 15 & $\mathrm{~ns}^{\mathrm{a}}$ \\
Gender (male/female) & $5 / 6$ & $6 / 9$ & $<0.05^{\mathrm{b}}$ \\
Age & $44.2 \pm 2.7$ & $65.2 \pm 3.4$ & $\mathrm{~ns}^{\mathrm{b}}$ \\
BMI & $21.4 \pm 1.1$ & $22.3 \pm 0.8$ & $\mathrm{~ns}^{\mathrm{b}}$ \\
Gastric mucosal atrophy (none-mild/moderate/severe) & $9 / 1 / 1$ & $8 / 4 / 3$ & $\mathrm{n} / \mathrm{a}$ \\
FSSG score & $\mathrm{n} / \mathrm{a}$ & $14.1 \pm 1.7$ & $\mathrm{n} / \mathrm{a}$ \\
pH of reflux (\%) & & $2 \pm 0.1$ & \\
$\quad$ Alkaline & $\mathrm{n} / \mathrm{a}$ & $85 \pm 4.9$ & $\mathrm{n} / \mathrm{a}$ \\
$\quad$ Weakly acid & & $13 \pm 1.2$ & $\mathrm{n} / \mathrm{a}$ \\
$\quad$ Acid & $\mathrm{n} / \mathrm{a}$ & $24 / 45(78)$ & $\mathrm{n} / \mathrm{a}$ \\
Total number of reflux, $N$ & $\mathrm{n} / \mathrm{a}$ & $41.2 \pm 5.2$ & $(47)$ \\
Reflux extending to the proximal esophagus, $n$ & $\mathrm{n} / \mathrm{a}$ & & \\
Proportion of reflux extending to the proximal esophagus $(\%)$ & & & \\
\hline
\end{tabular}

Values are expressed as mean \pm standard error of means (SEM) and mean/median (range). BMI, body mass index; FSSG, frequency scale for symptoms of gastroesophageal reflux disease; ns, not significant; n/a, not

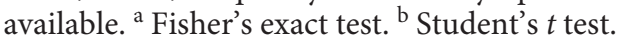

\section{Statistics}

All data are expressed as the mean \pm standard error of the means (SEM). Single comparisons were performed with Student's $t$ test, and multiple comparisons were performed with the TukeyKramer test. Correlations were calculated using Pearson's correlation coefficient, and proportional differences were evaluated by Fisher's exact test. Additionally, a generalized linear mixed-effect model (GLMM) was applied for analysis of repeated measures with multinomial explanatory variables, including an interaction with time and the groups, age of the subjects, and differences in subjects as a random effect. All analyses were conducted using $\mathrm{R}$ version 3.5.1 (http://www.R-project.org/). A $p$ value $<0.05$ was considered to indicate statistical significance.

\section{Results}

\section{Clinical Characteristics}

The difference in age between the patients and the controls reached statistical significance, but there were no significant differences in gender, BMI, or degree of gastric atrophy (Table 1). The mean FSSG score in the SI-positive group was $14.1 \pm 1.7$. Of the total reflux, $85.5 \pm 4.9 \%$ was weakly acidic reflux, and $41.2 \pm 5.2 \%$ extended to the proximal esophagus.

\section{Mucosal Integrity in the Proximal Esophagus Is Impaired in PPI-Refractory Patients with Nonerosive Reflux Disease}

The basal TEER (time $=0$ ) in biopsy specimens obtained from the proximal esophagus did not reach sig- nificant difference between the PPI-refractory patients with nonerosive reflux disease and the healthy controls $\left(15.2 \pm 3.9 \Omega \mathrm{cm}^{2}\right.$ vs. $14.8 \pm 3.9$, controls vs. patients, not significant [ns], Student's $t$ test). Although the TEER in the patients was lower than that of the controls in the distal esophagus, there was no significant difference between them $\left(12.8 \pm 2.8 \Omega \mathrm{cm}^{2}\right.$ vs. $9.7 \pm 2.3$, controls vs. patients, ns, Student's $t$ test). In our pilot study, exposure to the Krebs buffer solution with neutral $\mathrm{pH}$ did not cause apparent changes in TEER during $180 \mathrm{~min}$ in asymptomatic controls (data not shown). In the proximal esophageal samples subjected to continuous $\mathrm{pH} 4$ weak acid treatment, the TEER in the healthy controls increased transiently and then decreased steadily to the initial level, while that in the SI-positive patients continued to decrease over an experimental period of $180 \mathrm{~min}$ (Fig. 1). The difference in TEER between the patients and the controls was greatest at $60 \mathrm{~min}$ and then demonstrated a paralleled trajectory. The reduction in TEER in the patients ultimately yielded an $80 \%$ reduction at $180 \mathrm{~min}$ and reached statistical significance compared to that in the controls at all time points from 15 to $180 \mathrm{~min}$. Moreover, GLMM analysis demonstrated a statistically significant difference in the TEER between the patients and controls $(p<0.01)$. No interaction between time and the groups was observed $(p=0.07)$, and the differences in the age between the 2 groups was not associated with differences in the TEER in this analysis $(p=0.9)$, indicating that the younger age in the control group did not confound the 


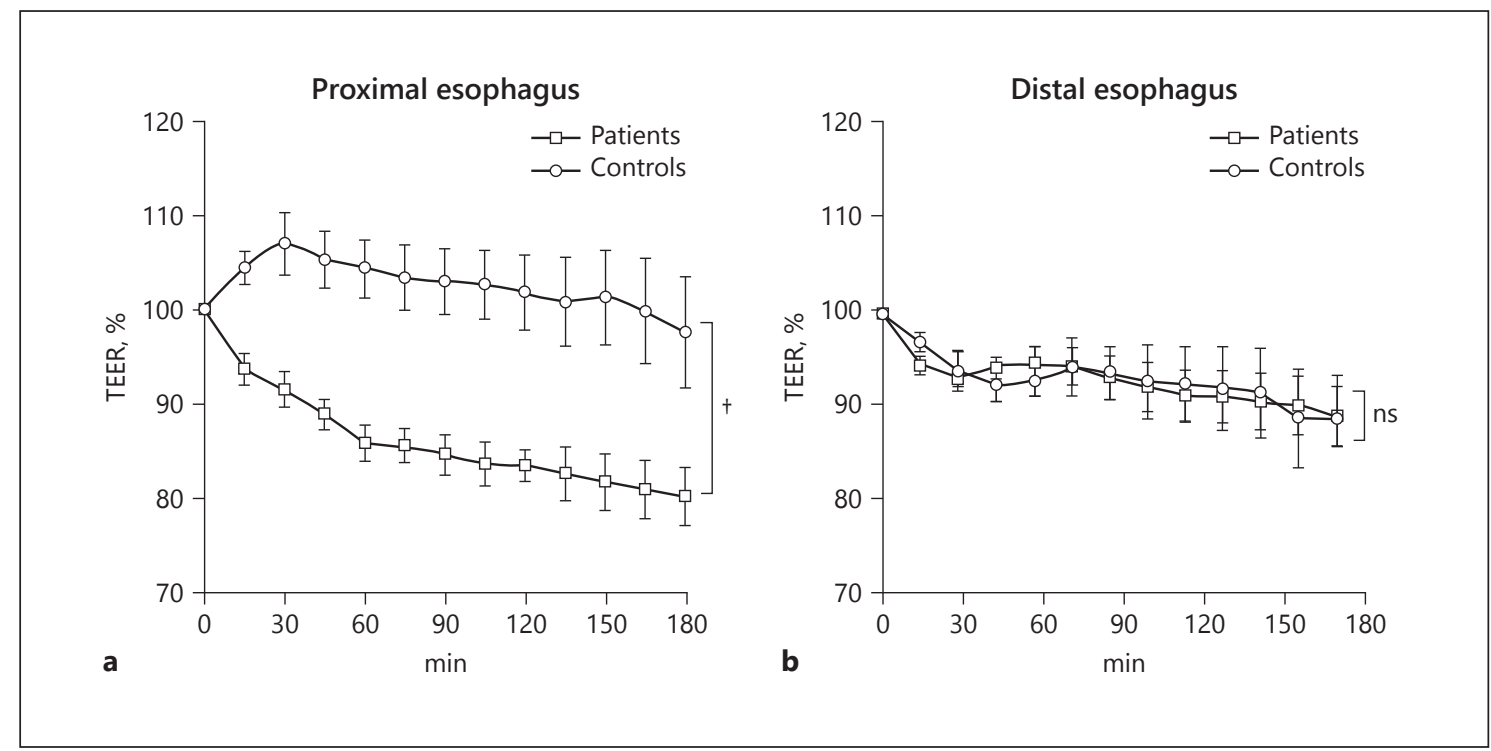

Fig. 1. TEER in the proximal esophagus. Biopsy samples obtained from esophageal mucosa were exposed to $\mathrm{pH}$ 4 normal saline for $180 \mathrm{~min}$. The mucosal integrity was evaluated by TEER using a mini-Ussing chamber. Changes in the TEER are expressed as percentages relative to the initial values. Each plotted data point represents the mean \pm SEM. a Proximal esophageal TEER (17 cm above the squamocolumnar junction). $\mathbf{b}$ Distal esophageal TEER ( $3 \mathrm{~cm}$ above the squamocolumnar junction). Open circle, healthy controls $(n=11)$; open square, PPI-refractory patients with nonerosive reflux disease $(n=15) ;{ }^{*} p<0.05$, significant difference at each time point using Student's $t$ test; $\dagger p<0.05$, significant difference evaluated using generalized linear mixed-effect model. TEER, transepithelial electrical resistance; ns, not significant.

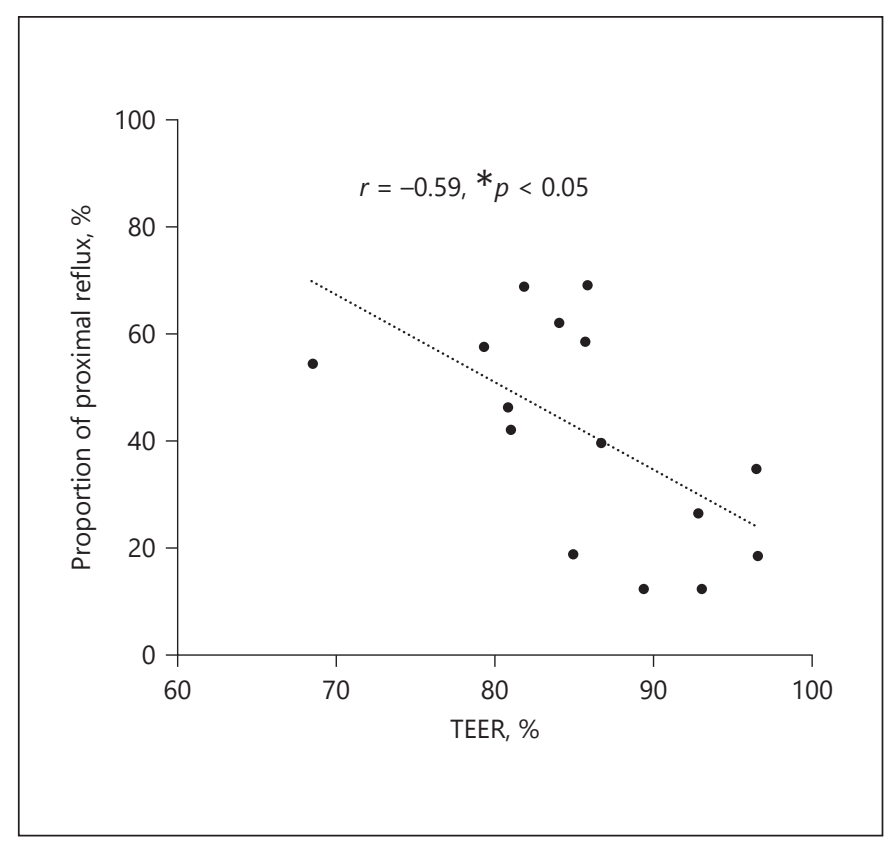

Fig. 2. Correlation plots for reduction in TEER and gastroesophageal reflux in the proximal esophagus in SI-positive patients. The proportion of the proximal reflux and the TEER at 60 min was plotted. $n=15,{ }^{*} p<0.05, r$; Pearson's correlation coefficient. TEER, transepithelial electrical resistance; SI, symptom index. results. Interestingly, in the distal esophagus, the weak acid exposure caused the TEER in the healthy controls to decrease continuously in a similar manner to that in the patients over the experimental period, and there was no significant difference between 2 groups at any time point during the experiments and in the regression analysis $(p=0.8)$.

The Impairment of Mucosal Integrity in the Proximal Esophagus Was Related to Reflux Extending to That

Site in the PPI-Refractory Patients with Nonerosive Reflux Disease

The reduction in proximal esophageal TEER represented a significantly negative correlation with the proportion of the reflux reaching to the proximal esophagus in the PPI-refractory patients with nonerosive reflux esophagitis (Fig. 2) while there was no statistically significant difference between the TEER and frequency of proximal reflux ( $r=-0.46$, ns) or total number of reflux $(r=-2.3, \mathrm{~ns})$. The statistical significance of the correlation between TEER and proportion of proximal reflux was observed at 60,75 , and $90 \mathrm{~min}$, and the greatest correlation was observed at $60 \mathrm{~min}(r=-0.59, p<0.05)$. The difference in TEER between the 2 groups reached a 
Fig. 3. Gene expression profiles of proximal esophageal mucosa. qPCR analysis of proximal esophageal tissue mRNA levels. Values represent gene expression relative to healthy controls. PPI-refractory patients with nonerosive reflux disease, $n=14$; controls, $n=10$; OCLN: occludin, SLCO2A1: solute carrier organic anion transporter family member $2 \mathrm{a} 1{ }^{*} p<0.05$, Student's $t$ test.
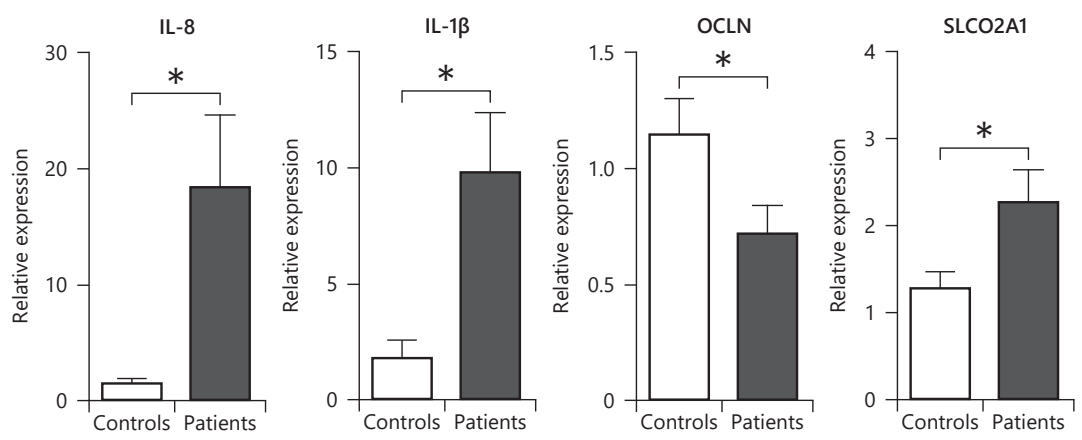

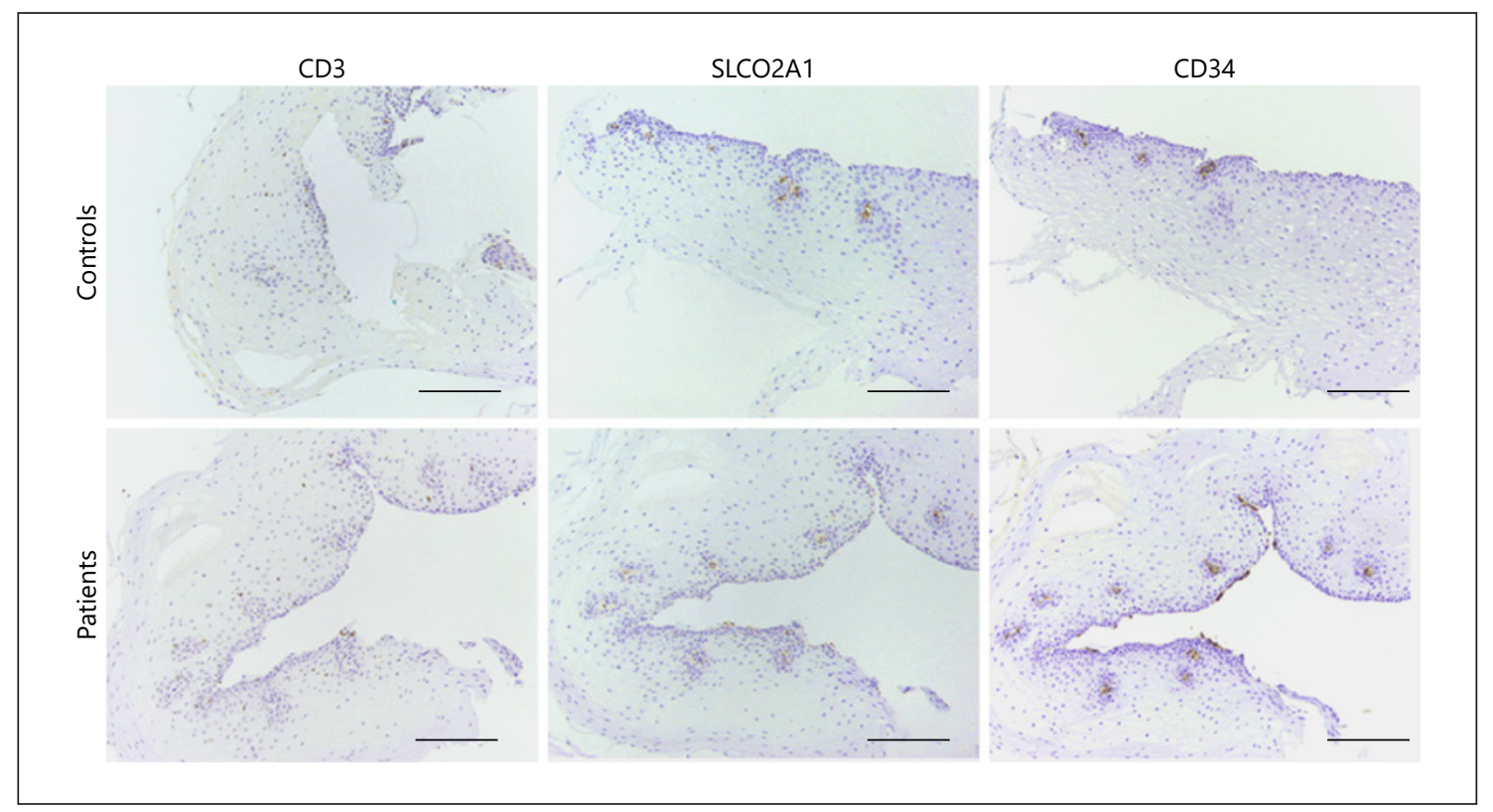

Fig. 4. Mucosal infiltration of CD3-positive lymphocytes and tissue expression of SLCO2A1 in proximal esophagus. Representative photomicrographs of a biopsy specimen immunostained with CD3, SLCO2A1, and CD34 in the PPI-refractory patients with nonerosive reflux disease and controls. Bar indicates $100 \mu \mathrm{m}$. SLCO2A1: solute carrier organic anion transporter family member $2 \mathrm{a} 1$.

maximum at this time point (Fig. 1); therefore, the value of TEER at $60 \mathrm{~min}$ was selected for further assessment.

\section{Altered Gene Expression Occurs in the Proximal}

Esophagus in PPI-Refractory Patients with Nonerosive Reflux Disease

RNA isolation failed in 1 sample from each group, and hence 14 patients and 10 controls were assessed for the gene expression. In the proximal esophagus, the $I L$ $1 \beta$ and $I L-8$ mRNA expression levels were increased in the patients, and the OCLN mRNA expression levels were decreased compared to those in the controls (Fig. 3). The SLCO2A1 mRNA expression levels were increased in the patients, but there was no difference in the TRPV1 mRNA expression levels between the patients and the controls (TRPV1; $1.4 \pm 0.3$ vs. $1.3 \pm 0.3$, controls vs. patients, ns). Moreover, in the distal esophagus, there was no significant difference between the TEER at $60 \mathrm{~min}$ and the mRNA expression levels of these genes (data not shown). On the other hand, in the distal esophagus, there was no difference between the 
Table 2. Association of TEER and clinicopathological features

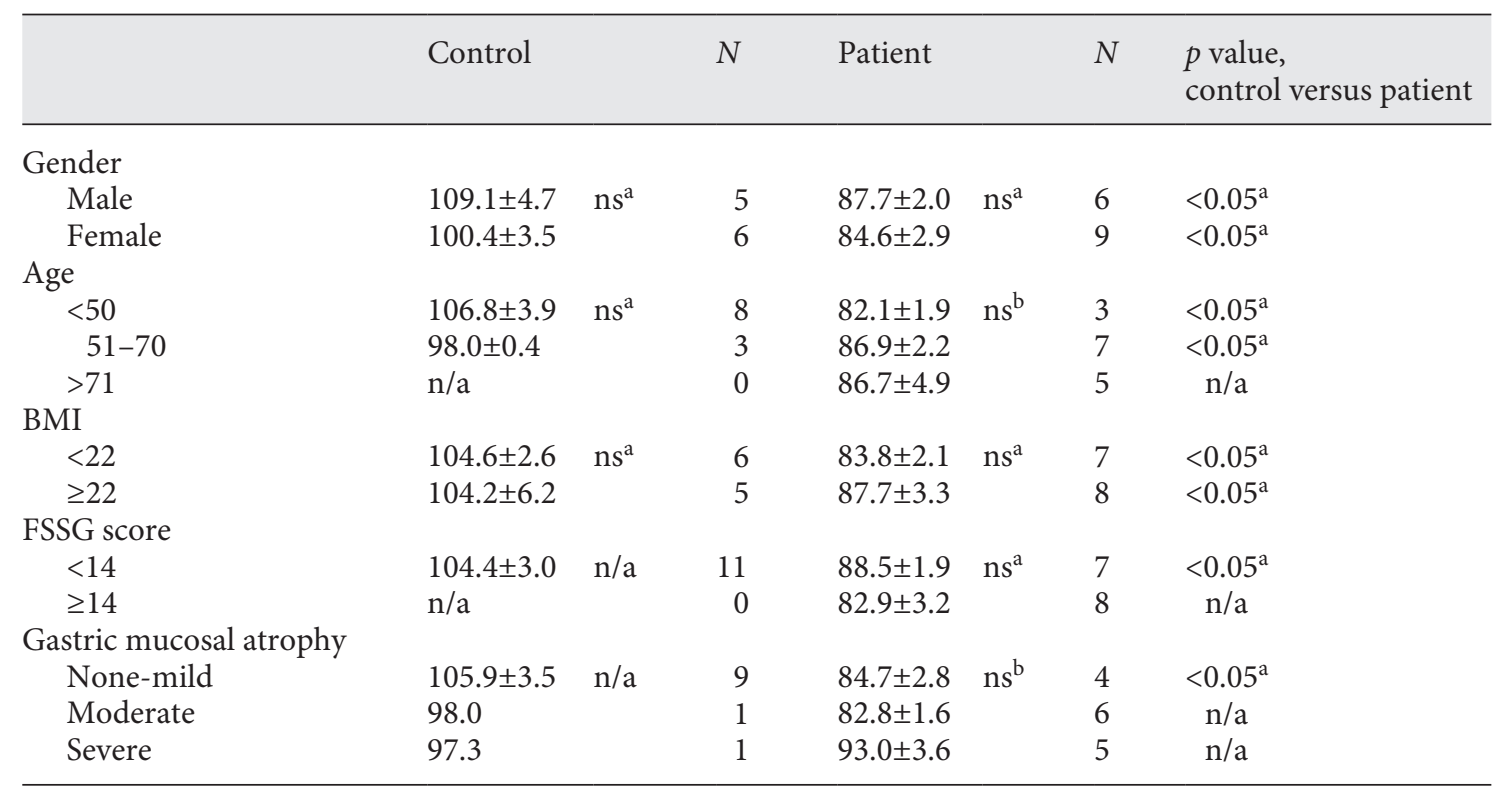

Values are \%change of TEER at the time of $60 \mathrm{~min}$ and expressed as mean \pm standard error of the means (SEM). The gastric mucosal atrophy was evaluated by the classification of Kimura and Takemoto; none-mild (none, $\mathrm{C}-1$, and $\mathrm{C}-2)$, moderate (C-3, O-1), or severe (O-2, O-3). FSSG, frequency scale for symptoms of

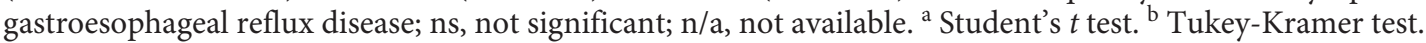

patients and controls in the mRNA expression levels of $I L-8, O C L N, S L C O 2 A 1$, and TRPV1 (IL-8; $5.4 \pm 3.0$ vs. $9.7 \pm 4.4, O C L N ; 1.9 \pm 1.8$ vs. $1.3 \pm 0.5, S L C O 2 A 1 ; 1.0 \pm$ 0.3 vs. $0.7 \pm 0.1, T R P V 1 ; 1.9 \pm 1.0$ vs. $1.6 \pm 0.4$ : controls vs. patients, ns, respectively) except $I L-1 \beta$ mRNA expression levels $(I L-1 \beta ; 2.3 \pm 1.0$ vs. $0.2 \pm 0.06$, controls vs. patients, $p<0.05)$.

\section{The PPI-Refractory Patients with Nonerosive} Reflux Disease Presented Mucosal Inflammation Concomitant with Increased Ion Channels for Molecules Related to Reflux Symptoms in the Proximal Esophagus

In the microscopic examination, scattered mononuclear cells were observed while polymorphonuclear cells or granulocytes were seldom seen in the proximal esophageal mucosa of either the patients or the controls (data not shown). Immunohistochemical examination demonstrated a slight increase in the infiltration of CD3-positive lymphocytes into the proximal esophageal mucosa of the patients compared to that of the healthy controls (Fig. 4). Moreover, consistent with the results of qPCR, increased mucosal expression of SLCO2A1 was demonstrated in the proximal esophagus of the patients, compared to that of the controls.
The SLCO2A1-positive cells were determined to be CD34positive intraepithelial microvascular cells, indicating that the increase in SLCO2A1 could be due to the increase in proliferation of the mucosal microvascular cells.

\section{Clinical Background Did Not Influence the Reduction} in Mucosal Integrity in the Proximal Esophagus

Under PPI administration, no factor, including age, gender, BMI, or gastric atrophy, influenced the reduction in proximal esophageal TEER in the PPI-refractory patients (Table 2). Moreover, the magnitude of the reflux symptoms evaluated by the FSSG was not correlated with the reduction in TEER (data not shown). On the other hand, statistically significant differences were observed in the TEER between the patients and controls in all evaluations subcategorized by the clinical characteristics $(p<$ 0.05).

\section{Discussion/Conclusion}

The major findings of this study are as follows: (1) The $\mathrm{pH} 4$ weak acid exposure apparently reduced the proximal esophageal levels of TEER in the PPI-refractory pa- 
tients with nonerosive reflux disease compared to those in the healthy controls, while a similar reduction was observed in the distal esophageal TEER between the 2 groups. (2) In the patients, the reflux extending to the proximal esophagus was related to the reduction of the TEER at that site. (3) The proximal esophageal mucosa in the patients presented evidently altered gene expression and histological changes related to mucosal inflammation and integrity as well as symptom perception. These results indicate that gastroesophageal reflux extending to the proximal esophagus damaged the mucosal barrier function at that site, which is likely to facilitate the perception of weakly acidic reflux.

A multifactorial pathogenesis underlies the reflux symptoms without erosive esophagitis, which are related the heterogenic composition of the patients [28]. Psychological stress and esophageal motility disorders were demonstrated to possibly cause heartburn-like symptoms unrelated to gastroesophageal reflux in patients with a negative SI despite the administration of PPI, which is subcategorized as functional heartburn (FH) excluding GERD [29]. Therefore, we focused on clarifying the mechanism underlying the PPI-refractory GERD symptoms induced by gastroesophageal reflux without ERD since PPI therapy for these patients is often ineffective in reducing the symptoms in the clinical setting.

Since the 24-h MII-pH measurement showed that approximately $85 \%$ of reflux episodes were weakly acidic reflux $(4<\mathrm{pH}<7)$ in the PPI-refractory patients who had a continuous double-dose PPI therapy, we evaluated the esophageal mucosal integrity against a $\mathrm{pH} 4$ weak acid solution in the current study. Additionally, we used tissue samples that were applied to the Ussing chamber analysis for PCR examination to reduce tissue sampling from human since previous studies secured the tissue viability up to $4 \mathrm{~h}[10,30]$. Considering the unified condition for treating samples as well as the time to alter SLCO2A1 protein expression, our results obtained by comparison between the patients and controls could be consistent even if the weakly acidic solution possibly deviated expression of the genes.

The mucosal burrier function in the distal esophagus in response to the $\mathrm{pH} 4$ weakly acid stimulation was almost at the same level in the patients and controls, while that in the proximal esophagus was apparently impaired in the patients compared to that in the controls. The difference in proximal esophageal TEERs occurred shortly after the exposure and last during the experiment period. Moreover, as with the previous studies, the exposure to the acidic solution transiently raised the proximal esoph-

Damaged Mucosal Barrier Function

Results in Hypersensitivity to Weak Acid ageal TEER in the controls. These findings suggest maintained protective reaction in the proximal mucosa against apical insults compared to that in the patients $[9,10]$ and support our recent study demonstrating that the distal reflux of weak acid was less likely to contribute to the development of reflux symptoms in nonerosive reflux disease despite PPI therapy [23]. Considering the lack of significant differences in the basal values of the proximal TEER between the patients and the controls, the dynamic change of the proximal TEER in response to the continuous stimulation of the weak acidic solution could represent functional vulnerability against weakly acid reflux in PPI-refractory patients with nonerosive reflux disease.

Thus far, several studies have demonstrated that proximal reflux of weakly acid is a major factor in the reflux perception of PPI-refractory GERD patients without severe esophageal mucosal injury [11, 22, 23]. The PPI-refractory patients in the current study represented a close association between the proximal reflux and the TEER reduction at that site, where reflux reaching the proximal esophagus damaged the mucosal ultrastructure, leading to a breakdown in the esophageal mucosal barrier function, since even weakly acid reflux could contribute to stimulating the intramucosal nociceptors and facilitate to cause reflux-related symptoms. This finding is supported by a previous study revealing that acid exposure in the proximal esophagus was perceived earlier than in the distal esophagus in the symptom association probability (SAP)-positive GERD patients [31].

The current study demonstrated some causative gene expressions and histological manifestations that could provide rational explanations for the mechanism underlying the PPI-refractory patients with nonerosive reflux disease. Although the differences in expression of gene were not evident in the distal esophagus, in accordance with the result of the previous study in GERD [32], the increased mRNA levels of $I L-1 \beta$ and $I L-8$ in the proximal esophagus could recruit CD3-positive lymphocytes into the mucosa in the patients. This finding suggests that reflux-inducing inflammation still remained despite the PPI therapy. This inflammation could cause a decrease in the mRNA levels of $O C L N$, a vulnerable molecule to acidinducing oxidative stress [33], leading to a decrease of TEER, as we reported previously [10]. Additionally, the proximal esophageal inflammation induced by acid reflux enhances the tissue angiogenic pathway [34], which increased the intraepithelial microvascular cells where SLCO2A1 is highly expressed [35]. Although the patients did not show enhanced TRPV1 mRNA levels in the pres- 
ent study, the increased SLCO2A1 might contribute to augmenting ATP and PGE2 secretion [19], which could not only lower the electrical impedance but also decrease the activation threshold of TRPV1 $[36,37]$. These findings suggest that the upregulated mucosal SLCO2A1 expression could partially contribute to the development of an esophagus perceptive to gastroesophageal reflux, even if in response to weakly acid reflux in the patients with reflux symptoms despite PPI therapy.

Some clinical features of nonerosive GERD were reported previously, for example, female-predominant gender difference, higher prevalence at low BMI, and relatively young age, compared to ERD [38]. The present study, however, showed that these clinical characteristics did not influence the changes in TEER under PPI-administered conditions. Moreover, the decrease of proximal esophageal TEER in the patients was not correlated to either reflux symptoms or the levels of gene expression. The levels of the TEER could not be associated to onset of reflux symptoms. Some undetermined factors including the involvement of other genes need to be elucidated for the etiology of the disease.

Although there was no statistically significant difference, the basal TEER in the distal esophagus was relatively decreased compared to the proximal esophagus in both the patients and the controls. Even asymptomatic healthy subjects presented gastroesophageal reflux confined to the distal esophagus, and patients with nonerosive reflux disease presented distal esophageal reflux more frequently than proximal reflux $[23,39]$. This finding of the current study mostly agreed with that in a previous study that demonstrated a significant decrease in the distal esophageal TEER compared to proximal one in a study with "off-PPI" GERD patients [31]. Moreover, some studies suggested that exposure to acidic or neutral $\mathrm{pH}$ solution decreased the distal esophageal TEER in nonerosive GERD patients compared to the asymptomatic subjects, suggesting an impairment of the distal esophageal integrity contributed to provoking reflux symptoms $[11,31]$. The stimulations to the biopsy samples in the previous studies were different from those in the present study, and different stimulations were reported to result in different responses in the TEER measurement [40]. A recent study revealed differences in the afferent nerve location in the distal esophagus between patients with nonerosive reflux disease and asymptomatic subjects, which might contribute to reflux hypersensitivity [41]. On the other hand, we presented the changes in the proximal esophageal TEER against exposure to weakly acid without no difference in the basal TEER. Elu- cidation of the difference between dynamic and static function in proximal esophageal mucosa might be crucial to clarify mechanism of reflux perception in PPI-refractory patients with nonerosive reflux disease. In addition to the involvement of the distal esophageal mucosal integrity, further study is still needed about the relationship between kinds of stimulant and alternation in mucosal integrity and nerve activation, and a follow-up survey for TEER measurements to the patients with or without PPI response is also needed.

In conclusion, using an ex vivo model with human biopsy specimens, this study is the first to demonstrate a profound decrease in the mucosal integrity of the proximal esophagus in PPI-refractory patients with nonerosive reflux disease. The current study presents one of the putative mechanisms in esophageal hypersensitivity to gastric reflux and might contribute to new therapeutic strategies for those who suffer from the perception of weakly acid reflux.

\section{Statement of Ethics}

This study was conducted according to the provisions of the Declaration of the Helsinki and approved by the Ethics Committee of Tohoku University Hospital (2017-1-734). All subjects have given their written informed consent.

\section{Conflict of Interest Statement}

There was no disclosure of financial arrangements related to the research or assistance with manuscript preparation.

\section{Funding Sources}

This study was supported in part by Grant-in-Aid from Japan Society for the Promotion of Science (15K08945).

\section{Author Contributions}

Study conception and design: K. Asanuma and T. Koike. Acquisition of data: K. Norita, T. Fujiya, Y. Abe, and T. Koike. Analysis and interpretation of data: K. Asanuma, W. Hatta, K. Nakagawa, T. Nakamura, and N. Nakaya. Drafting of the manuscript: K. Norita and K. Asanuma. Critical revision: K. Uno, N. Asano, A. Imatani, T. Shimosegawa, and A. Masamune. Writing of the manuscript: K. Asanuma and T. Koike. All authors approved the final version of the manuscript and agree to be accountable for all aspects of the work in ensuring that questions related to the accuracy or integrity of any part of the work were appropriately investigated and resolved. 
1 Miwa H, Oshima T, Tomita T, Kim Y, Hori K, Matsumoto T. Gastro-esophageal reflux disease: the recent trend in Japan. Clin J Gastroenterol. 2008 Dec;1(4):133-8.

2 Iijima K, Koike T, Abe Y, Ohara S, Shimosegawa $\mathrm{T}$. A chronological increase in gastric acid secretion from 1995 to 2014 in young Japanese healthy volunteers under the age of 40 years old. Tohoku J Exp Med. 2016;239(3): 237-41.

3 Fujiwara Y, Arakawa T. Epidemiology and clinical characteristics of GERD in the Japanese population. J Gastroenterol. 2009;44(6): 518-34.

4 Bytzer P, van Zanten SV, Mattsson H, Wernersson B. Partial symptom-response to proton pump inhibitors in patients with non-erosive reflux disease or reflux oesophagitis - a post hoc analysis of 5796 patients. Aliment Pharmacol Ther. 2012 Oct;36(7):635-43.

5 Sigterman KE, van Pinxteren B, Bonis PA, Lau J, Numans ME. Short-term treatment with proton pump inhibitors, H2-receptor antagonists and prokinetics for gastro-oesophageal reflux disease-like symptoms and endoscopy negative reflux disease. Cochrane Database Syst Rev.2013 May31(5):CD002095.

6 Armstrong D, Talley NJ, Lauritsen K, Moum B, Lind $\mathrm{T}$, Tunturi-Hihnala $\mathrm{H}$, et al. The role of acid suppression in patients with endoscopynegative reflux disease: the effect of treatment with esomeprazole or omeprazole. Aliment Pharmacol Ther. 2004 Aug 15;20(4):413-21.

7 Uemura N, Inokuchi H, Serizawa H, Chikama T, Yamauchi M, Tsuru T, et al. Efficacy and safety of omeprazole in Japanese patients with nonerosive reflux disease. J Gastroenterol. 2008;43(9):670-8.

8 Yang XJ, Jiang HM, Hou XH, Song J. Anxiety and depression in patients with gastroesophageal reflux disease and their effect on quality of life. World J Gastroenterol. 2015 Apr 14; 21(14):4302-9.

9 Ara N, Iijima K, Asanuma K, Yoshitake J, Ohara S, Shimosegawa T, et al. Disruption of gastric barrier function by luminal nitrosative stress: a potential chemical insult to the human gastro-oesophageal junction. Gut. 2008 Mar;57(3):306-13.

10 Honda J, Iijima K, Asanuma K, Ara N, Shiroki T, Kondo Y, et al. Estrogen enhances esophageal barrier function by potentiating occludin expression. Dig Dis Sci. 2016 Apr; 61(4):1028-38.

11 Woodland P, Lee C, Duraisamy Y, Farre R, Dettmar P, Sifrim D. Assessment and protection of esophageal mucosal integrity in patients with heartburn without esophagitis. Am J Gastroenterol. 2013 Apr;108(4):535-43.

12 Farre R, Fornari F, Blondeau K, Vieth M, De Vos R, Bisschops R, et al. Acid and weakly acidic solutions impair mucosal integrity of distal exposed and proximal non-exposed human oesophagus. Gut. 2010 Feb;59(2):164-9.
13 Weijenborg PW, Smout AJ, Verseijden C, van Veen HA, Verheij J, de Jonge WJ, et al. Hypersensitivity to acid is associated with impaired esophageal mucosal integrity in patients with gastroesophageal reflux disease with and without esophagitis. Am J Physiol Gastrointest Liver Physiol. 2014 Aug 1; 307(3):G323-9.

14 Lundell LR, Dent J, Bennett JR, Blum AL, Armstrong D, Galmiche JP, et al. Endoscopic assessment of oesophagitis: clinical and functional correlates and further validation of the Los Angeles classification. Gut. 1999 Aug; 45(2):172-80.

15 Mönkemüller K, Wex T, Kuester D, Fry LC, Peitz U, Beyer M, et al. Interleukin-1beta and interleukin-8 expression correlate with the histomorphological changes in esophageal mucosa of patients with erosive and non-erosive reflux disease. Digestion. 2009;79(3): $186-95$.

16 Kim JJ, Kim N, Park JH, Kim YS, Lee SM, Lee $\mathrm{DH}$, et al. Comparison of tight junction protein-related gene mRNA expression levels between male and female gastroesophageal reflux disease patients. Gut Liver. 2018 Jul 15; 12(4):411-9.

17 Guarino MP, Cheng L, Ma J, Harnett K, Biancani $\mathrm{P}$, Altomare A, et al. Increased TRPV1 gene expression in esophageal mucosa of patients with non-erosive and erosive reflux disease. Neurogastroenterol Motil. 2010 Jul; 22(7):746-e219.

18 Kondo T, Oshima T, Tomita T, Fukui H, Watari J, Okada H, et al. Prostaglandin E(2) mediates acid-induced heartburn in healthy volunteers. Am J Physiol Gastrointest Liver Physiol. 2013 Mar 15;304(6):G568-73.

19 Sabirov RZ, Merzlyak PG, Okada T, Islam MR, Uramoto $\mathrm{H}$, Mori $\mathrm{T}$, et al. The organic anion transporter SLCO2A1 constitutes the core component of the Maxi- $\mathrm{Cl}$ channel. EMBO J. 2017 Nov 15;36(22):3309-24.

$20 \mathrm{Wu}$ L, Oshima T, Fukui H, Watari J, Miwa H. Adenosine triphosphate induces $\mathrm{P} 2 \mathrm{Y} 2$ activation and interleukin- 8 release in human esophageal epithelial cells. J Gastroenterol Hepatol. 2017 Jul;32(7):1341-7.

21 Tutuian R, Vela MF, Hill EG, Mainie I, Agrawal A, Castell DO. Characteristics of symptomatic reflux episodes on acid suppressive therapy. Am J Gastroenterol. 2008 May; 103(5):1090-6.

22 Zerbib F, Duriez A, Roman S, Capdepont M, Mion F. Determinants of gastro-oesophageal reflux perception in patients with persistent symptoms despite proton pump inhibitors. Gut. 2008 Feb;57(2):156-60.

23 Nakagawa K, Koike T, Iijima K, Saito M, Kikuchi H, Hatta W, et al. Characteristics of symptomatic reflux episodes in Japanese proton pump inhibitor-refractory non-erosive reflux disease patients. World J Gastroenterol. 2015 Dec 21;21(47):13352-9.
24 Kusano M, Hosaka H, Kawada A, Kuribayashi S, Shimoyama Y, Kawamura O, et al. Development and evaluation of a modified frequency scale for the symptoms of gastroesophageal reflux disease to distinguish functional dyspepsia from non-erosive reflux disease. J Gastroenterol Hepatol. 2012 Jul; 27(7):1187-91.

25 Wiener GJ, Richter JE, Copper JB, Wu WC, Castell DO. The symptom index: a clinically important parameter of ambulatory 24-hour esophageal $\mathrm{pH}$ monitoring. Am J Gastroenterol. 1988 Apr;83(4):358-61.

26 Kimura K, Takemoto T. An endoscopic recognition of the atrophic border and its significance in chronic gastritis. Endoscopy. 1969; 1(03):87-97.

27 Takahashi Y, Uno K, Iijima K, Abe Y, Koike $\mathrm{T}$, Asano N, et al. Acidic bile salts induces mucosal barrier dysfunction through let-7a reduction during gastric carcinogenesis after Helicobacter pylori eradication. Oncotarget. 2018 Apr 6;9(26):18069-83.

28 Savarino E, Coletta MD. Oesophagus: symptom perception in patients with NERD: do nerves matter? Nat Rev Gastroenterol Hepatol. 2017 Nov;14(11):634-6.

29 Savarino E, Zentilin P, Tutuian R, Pohl D, Gemignani L, Malesci A, et al. Impedance-pH reflux patterns can differentiate non-erosive reflux disease from functional heartburn patients. J Gastroenterol. 2012 Feb;47(2):15968.

30 Le Ferrec E, Chesne C, Artusson P, Brayden D, Fabre G, Gires P, et al. In vitro models of the intestinal barrier. The report and recommendations of ECVAM Workshop 46. European Centre for the Validation of Alternative Methods. Altern Lab Anim. 2001 Nov-Dec; 29(6):649-68.

31 van Hoeij FB, Weijenborg PW, van den Bergh Weerman MA, van den Wijngaard RM, Verheij J, Smout AJ, et al. Mucosal integrity and sensitivity to acid in the proximal esophagus in patients with gastroesophageal reflux disease. Am J Physiol Gastrointest Liver Physiol. 2016 Jul 1;311(1):G117-22.

32 Fitzgerald RC, Onwuegbusi BA, Bajaj-Elliott M, Saeed IT, Burnham WR, Farthing MJ. Diversity in the oesophageal phenotypic response to gastro-oesophageal reflux: immunological determinants. Gut. 2002 Apr;50(4): 451-9.

33 Blasig IE, Bellmann C, Cording J, Del Vecchio $\mathrm{G}$, Zwanziger $\mathrm{D}$, Huber $\mathrm{O}$, et al. Occludin protein family: oxidative stress and reducing conditions. Antioxid Redox Signal. 2011 Sep 1; 15(5):1195-219.

34 Taddei A, Fabbroni V, Pini A, Lucarini L, Ringressi MN, Fantappiè $\mathrm{O}$, et al. Cyclooxygenase- 2 and inflammation mediators have a crucial role in reflux-related esophageal histological changes and Barrett's esophagus. Dig Dis Sci. 2014 May;59(5):949-57.
Damaged Mucosal Barrier Function

Results in Hypersensitivity to Weak Acid
Digestion 2021;102:404-414

DOI: $10.1159 / 000508661$ 
35 Topper JN, Cai J, Stavrakis G, Anderson KR, Woolf EA, Sampson BA, et al. Human prostaglandin transporter gene (hPGT) is regulated by fluid mechanical stimuli in cultured endothelial cells and expressed in vascular endothelium in vivo. Circulation. 1998 Dec 1; 98(22):2396-403.

36 Dai Y, Moriyama T, Higashi T, Togashi K, Kobayashi K, Yamanaka H, et al. Proteinaseactivated receptor 2-mediated potentiation of transient receptor potential vanilloid subfamily 1 activity reveals a mechanism for proteinase-induced inflammatory pain. J Neurosci. 2004 May 5;24(18):4293-9.
37 Maeda T, Inagaki M, Fujita Y, Kimoto T, Tanabe-Fujimura C, Zou K, et al. ATP increases the migration of microglia across the brain endothelial cell monolayer. Biosci Rep. 2016; 36(2):e00318.

38 Fass R. Erosive esophagitis and nonerosive reflux disease (NERD): comparison of epidemiologic, physiologic, and therapeutic characteristics. J Clin Gastroenterol. 2007 Feb; 41(2):131-7.

39 Shay S, Tutuian R, Sifrim D, Vela M, Wise J, Balaji N, et al. Twenty-four hour ambulatory simultaneous impedance and $\mathrm{pH}$ monitoring: a multicenter report of normal values from 60 healthy volunteers. Am J Gastroenterol. 2004 Jun;99(6):1037-43.
40 Marcus EA, Vagin O, Tokhtaeva E, Sachs G, Scott DR. Helicobacter pylori impedes acidinduced tightening of gastric epithelial junctions. Am J Physiol Gastrointest Liver Physiol. 2013 Nov 15;305(10):G731-9.

41 Woodland P, Shen Ooi JL, Grassi F, Nikaki K, Lee C, Evans JA, et al. Superficial esophageal mucosal afferent nerves may contribute to reflux hypersensitivity in nonerosive reflux disease. Gastroenterology. 2017 Nov; 153(5): $1230-9$. 